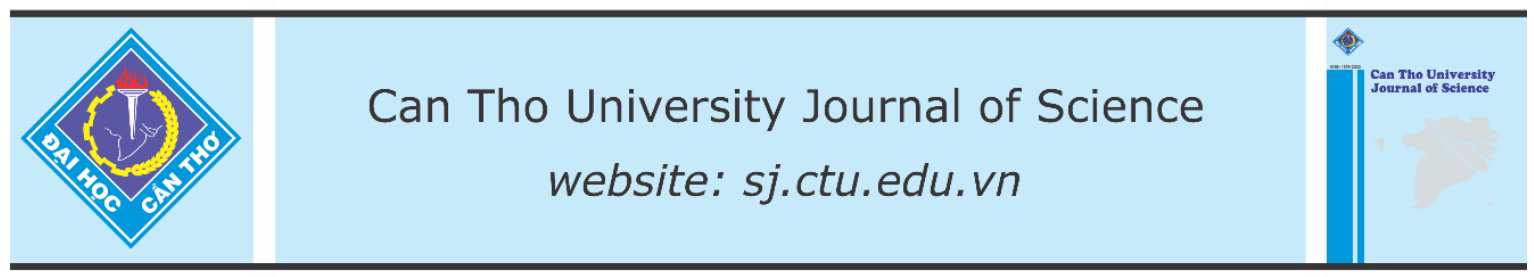

DOI: 10.22144/ctu.jen.2021.014

\title{
Effects of stocking density on performance of snubnose pompano juvenile (Trachinotus blochii) reared in recirculating system
}

\author{
Tran Ngoc Hai ${ }^{1 *}$, Tran Nguyen Duy Khoa ${ }^{1}$, Kotani Tomonari ${ }^{2}$, Ly Van Khanh ${ }^{1}$ and Le Quoc Viet ${ }^{1}$ \\ ${ }^{1}$ College of Aquaculture and Fisheries, Can Tho University, Viet Nam \\ ${ }^{2}$ Faculty of Fisheries, Kagoshima University, Japan \\ *Correspondence: Tran Ngoc Hai (email: tnhai@ctu.edu.vn)
}

\section{Article info.}

Received 22 Feb 2021

Revised 21 May 2021

Accepted 04 Jun 2021

\section{Keywords}

Stocking density Trachinotus blochii, recirculating system

\begin{abstract}
This study aimed to determine appropriate densities for rearing pompano juvenile (Trachinotus blochii) in a recirculating system. Four treatments of stocking density were evaluated including 500, 1.000, 1.500, and 2.000 inds $/ \mathrm{m}^{3}$ in triplicate. The experimental system for pompano rearing was designed with 120-L tanks connected to 1 settling tank, 1 filter tank, 1 stone filter tank (contained $250 \mathrm{~L}$ of filter volume for each tank). The system was fulfilled with marine water at $30 \%$ of salinity and aerated continuously. Pompano were initially stocked at $0.07 \pm 0.03 \mathrm{~g} /$ fish of body weight and daily fed using commercial pellet contained $55 \%$ of crude protein. After 30 days of rearing, the fish stocked at 1.000 individuals $/ \mathrm{m}^{3}$ showed the best results in growth rate $(0.060 \mathrm{~g} /$ day of DWG and $10.97 \% /$ day of SGR) and was significantly higher than the treatment stocked at 1,500 and 2,000 inds $/ m^{3}(p<0.05)$, however, no significant difference was observed between 1,000 and 500 treatments ( $p>0.05$ ).
\end{abstract}

\section{INTRODUCTION}

The rapid expansion of aquaculture sector in recent years leads to several issues in water usage and environmental pollution (Zhang et al., 2011). Recirculating aquaculture system (RAS) has been highlighted as an eco-friendly system in aquaculture production with advantages in increasing fish production while conserving water, improving overall waste capture efficiency, and improving water quality for a variety of freshwater and marine fish species (Timmons et al. 1998; Pfeiffer and Riche, 2011; Badiola et al., 2012). RAS was wildly applied in the hatchery and commercial production of several aquatic species such as white leg shrimp (Suantika et al., 2018), rainbow trout Oncorhynchus mykiss (Pulkkinen et al., 2018), Nile tilapia Oreochromis niloticus (Sri-uam et al., 2016), and cobia
Rachycentron canadum (Díaz-Muñoz et al., 2019), whereby the promising results were remarked. However, high stocking density and fish growth resulting in increased metabolic wastes, the exchange rates in RAS are reduced and the concentrations of a variety of water constituents increase; this deterioration of water quality may affect fish growth (Pulkkinen et al., 2018; Shao et al., 2019).

Stocking density is a pivotal factor affecting fish welfare in the aquaculture industry, especially RAS where high densities in confined environments are aimed at high productivity (Espinal \& Matuli, 2019). Previous studies have reported that stocking density is one of the most important variables affecting fish growth, health, metabolism and welfare (Costas et al., 2008; Laiz-Carrión et al., 2012; Ni et al., 2014; Shao et al., 2019). Moreover, the inverse 
growth in cultured fishes was related to stocking density due to social interactions (Irwin et al., 1999; Ellis et al., 2002). Inappropriate stocking densities might result in reduction of growth and immune competence due to factors such as social interactions and deterioration of water quality, which can affect both feed intake and FCR of the fish (Chavez et al., 2011).

Snubnose pompano (Trachinotus blochii) has been considered an economically important fish for marine aquaculture due to high market value, rapid growth and high adaption to formulated feed (Chavez et al., 2011; Teletchea, 2015). This study was carried out to evaluate the effect of different stocking densities on the growth performance, survival rate and biomass of $T$. blochii juvenile reared in RAS.

\section{MATERIALS AND METHODS}

\subsection{Experimental design and fish culture}

Four treatments of stocking density were evaluated including 500 (NT1); 1,000 (NT2); 1,500 (NT2); and 2,000 (NT4) fish $/ \mathrm{m}^{3}$ in triplicate. The RAS system for pompano rearing was designed with 120 -L tanks connected to 1 settling tank, 1 filter tank, 1 stone filter tank (each tank contained $250 \mathrm{~L}$ of filter volume). The RAS was fulfilled with marine water at $30 \%$ of salinity and operated with continuous aeration for one week before stocking fish. The experiment was set up randomly and lasted for 30 days.

The juveniles of T. blochii were produced from Marine hatchery in College of Aquaculture and Fisheries, Can Tho University and acclimated for 1 week in RAS system. During the acclimation, the fish were satisfied fed twice a day at $8 \mathrm{AM}$ and $3 \mathrm{PM}$ using commercial pellets (containing $55 \%$ of protein, $9 \%$ of lipid, and $1.9 \%$ of fiber). After 1 week, the active, uniform size and healthy juveniles were selected and transferred to the experimental RAS system at designed densities.

\subsection{Management and sampling}

During the experimental period, the fishes were satisfied fed four times per day at $7 \mathrm{AM}, 10 \mathrm{AM}, 2 \mathrm{PM}$ and 5 PM following the protocol in Table 1. Dissolved oxygen (DO), temperature, and $\mathrm{pH}$ were monitored twice daily (at $7 \mathrm{AM}$ and $2 \mathrm{AM}$ ) using a digital meter (HI-98196 Multi-Parameter Waterproof Meter, HANNA Instruments, Ltd.). Total ammonium nitrogen (TAN), nitrite/nitrate and alkalinity were measured every 3 days by Sera test kits (Germany). The light density exposed to the systems was recorded four times daily (at 6 AM, 9 AM, 12 $\mathrm{AM}, 3 \mathrm{PM}$, and 6 PM) using an EasyView ${ }^{\mathrm{TM}}$ wide range light meter (Extech EA30).

Table 1. The feeding protocol and proximate compositions of feed

\begin{tabular}{llll}
\hline Day & Code & Size $(\boldsymbol{\mu m})$ & Proximate composition \\
\hline $1-10$ & NRD 3/5 & $300-500$ & Protein 55\%, Lipid 9\% \\
$10-20$ & NRD 5/8 & $500-800$ & Fiber 1.9\%, Moisture 8\% \\
$20-30$ & N46L & $800-1.000$ & $\begin{array}{l}\text { Protein 46\%, Fiber 5\% } \\
\text { Lipid 10\%, Calcium 3.5 \%, Phosphorus 2.5\%. }\end{array}$ \\
\hline
\end{tabular}

Random sampling was conducted every 10 days wherein 30 fishes per tank were individually measured body weight and total length. At the end of the experiment, the fish were harvested to determine the survival rate (SR), daily weight gain (DWG), specific growth rate (SGR), daily length gain (DLG) and specific growth rate in length (SGRL) as follows:

$$
\mathrm{DWG}=\frac{\text { Final weight }- \text { Initial weight }}{\text { Day of culture }}
$$

$$
\begin{aligned}
& \text { SRG }(\%) \\
& =\frac{100 *(\text { Ln final weight }- \text { Ln initial weight })}{\text { Day of culture }} \\
& \text { DWG }=\frac{\text { Final weight }- \text { Initial weight }}{\text { Day of culture }}
\end{aligned}
$$

$$
\text { DLG }=\frac{\text { Final length }- \text { Initial length }}{\text { Day of culture }}
$$

$$
\begin{aligned}
& \text { SGRL }(\%) \\
& =\frac{100 *(\text { Ln Final length }- \text { Ln Initial length })}{\text { Day of culture }} \\
& \text { SR }(\%)=\frac{\text { Final stock } * 100}{\text { Inital stock }}
\end{aligned}
$$

\subsection{Statistical Analysis}

Data were presented as mean \pm standard division (SD) and were subjected to one-way ANOVA (SPSS 16.0 for Windows, IBM, Armonk, NY, USA) and Duncan's test was applied. All differences were considered at $\alpha=0.05$. 


\section{RESULTS AND DISCUSSION}

\subsection{Dissolved oxygen (DO), temperature, $\mathrm{pH}$, light density}

During the experimental period, the temperature ranged from $28^{\circ} \mathrm{C}$ to $31.5^{\circ} \mathrm{C}, \mathrm{pH}$ values fluctuated from 7.7 to 8.3 and DO was within 4.5 to $5.4 \mathrm{mg} / \mathrm{L}$. However, there was no significant difference among treatments (Table 2). Previous studies highlighted that the optimal temperature for pompano was within 18 and $31^{\circ} \mathrm{C}$, in which the juvenile rearing required an appropriate range from $27^{\circ} \mathrm{C}$ to $31^{\circ} \mathrm{C}$ (Hanh, 2007; Ha, 2014). Several studies reported that temperature significantly affected the fish survival, metabolism, food intake, swimming speed and cost of transport (Brest et al., 1996; McCarthy et al., 1998; Claireaux et al., 2006). Therefore, the temperature was an important factor that required maintaining an appropriate range during the

Table 2. The average values of temperature, $\mathrm{pH}$ and DO

\begin{tabular}{lrrrrrr}
\hline \multirow{2}{*}{ Treatment } & \multicolumn{2}{c}{ Temperature $\left({ }^{\circ} \mathbf{C}\right)$} & \multicolumn{2}{c}{ pH } & \multicolumn{2}{c}{ DO $(\mathbf{m g} / \mathbf{L})$} \\
\cline { 2 - 7 } & $\mathbf{7 ~ A M}$ & $\mathbf{2 ~ P M}$ & $\mathbf{7 ~ A M}$ & $\mathbf{2 ~ P M}$ & $\mathbf{7 ~ A M}$ & $\mathbf{2 ~ P M}$ \\
\hline NT1 & $28.7 \pm 0.2$ & $31.2 \pm 0.3$ & $8.0 \pm 0.2$ & $8.1 \pm 0.2$ & $4.9 \pm 0.5$ & $4.6 \pm 0.3$ \\
NT2 & $28.7 \pm 0.3$ & $31.2 \pm 0.2$ & $8.0 \pm 0.1$ & $8.1 \pm 0.2$ & $4.8 \pm 0.3$ & $4.6 \pm 0.2$ \\
NT3 & $28.8 \pm 0.1$ & $31.2 \pm 0.1$ & $7.9 \pm 0.2$ & $8.0 \pm 0.2$ & $4.8 \pm 0.3$ & $4.5 \pm 0.3$ \\
NT4 & $28.6 \pm 0.2$ & $31.2 \pm 0.2$ & $8.0 \pm 0.1$ & $8.0 \pm 0.1$ & $4.9 \pm 0.1$ & $4.6 \pm 0.1$ \\
\hline
\end{tabular}

Table 3. The average light density exposure to the RAS

\begin{tabular}{lrrrrr}
\hline \multirow{2}{*}{ Treatment } & \multicolumn{5}{c}{ Light density (lux) } \\
\cline { 2 - 6 } & $\mathbf{6 ~ A M}$ & $\mathbf{9 A M}$ & $\mathbf{1 2}$ AM & $\mathbf{3 ~ P M}$ & $\mathbf{6 ~ P M}$ \\
\hline NT1 & $51 \pm 2$ & $2.914 \pm 407$ & $4.953 \pm 959$ & $3.042 \pm 326$ & $35 \pm 1$ \\
NT2 & $51 \pm 5$ & $3.100 \pm 310$ & $5.067 \pm 462$ & $3.420 \pm 261$ & $34 \pm 2$ \\
NT3 & $55 \pm 3$ & $3.355 \pm 322$ & $5.854 \pm 636$ & $3.575 \pm 267$ & $37 \pm 2$ \\
NT4 & $54 \pm 5$ & $3.415 \pm 353$ & $6.168 \pm 126$ & $3.748 \pm 220$ & $36 \pm 1$ \\
\hline
\end{tabular}

The light density (lux) among treatments significantly fluctuated during the day-night cycle (Table 3). However, there was no remarkable difference in light density among treatments. According to Batty et al. (1990), and Didrikas and Hansson (2009), most pelagic fish are visual predators, whereby their behavior and activity are strongly affected by the diel light cycle and density. In which, the fish swimming speed and feeding behavior associated with bioenergetics models of fish. Therefore, light density is an important factor that needs to consider for the culture systems, especially for the indoor RAS systems.

\subsection{Total ammonia, nitrite and alkalinity}

In RAS system operation, water quality is an important function that relates to the stability of the culture systems. In which, the bacterial communities play a central role in maintaining water experiment. Besides, the $\mathrm{pH}$ value in this study was in line with the optimal range (7.5 to 8.7) for pompano rearing suggested by Hanh (2007) and Dung (2015). Importantly, optimal physicochemical parameters of water quality are essential to a healthy, balanced, and functioning aquaculture system (Kramer, 1987; Makori et al., 2017). In which, the DO level in water is a critical factor that affects the growth, survival, distribution, behavior, and physiology of fish (Kramer, 1987). A range of DO from 4.5 to $5.4 \mathrm{mg} / \mathrm{L}$ in this study is acceptable for the rearing phase of fish (Sim et al., 2005; Moretti et al., 2005; Hanh, 2007). However, for intensive aquaculture production operated RAS, the DO level $>5 \mathrm{ppm}$ was essential to support good fish production due to the high DO consumption of fish and micro-community in the system (Makori et al., 2017; Duarte et al., 2019). quality (Rurangwa \& Verdegem, 2015). The results from this study showed low levels and narrow variation ranges of TAN, nitrite during the experimental time. The TAN concentration among treatments ranged from 0.5 to $0.64 \mathrm{mg} / \mathrm{L}$, while nitrite was from 0.9 to $1.15 \mathrm{mg} / \mathrm{L}$ (Table 4 ). However, no significant difference in TAN and nitrite was recorded among treatments. According to Galvan et al. (2016), TAN and nitrite levels in RAS systems should be controlled at lower than $5 \mathrm{mg} / \mathrm{L}$. But a concentration at $<0.1 \mathrm{mg} / \mathrm{L}$ of TAN and $1.5-2 \mathrm{mg} / \mathrm{L}$ of nitrite for marine hatchery (Sim et al., 2005; Moretti et al., 2005; Kroupova et al., 2005; Jayakumar \& Nazar, 2013). Moreover, these levels gradually increased along with the increase in fish age-size, therefore, the fish could adapt accordingly. Low and stable levels of TAN and nitrite in this study also indicated that the RAS was functionally and stably operated during the experiment. 
Table 4. The average values of nitrite, TAN and alkalinity in treatments during the experimental period

\begin{tabular}{lrrr}
\hline Treatment & Nitrite $(\mathbf{m g} / \mathbf{L})$ & TAN $(\mathbf{m g} / \mathbf{L})$ & Alkalinity $(\mathbf{m g ~ C a C O} / \mathbf{L})$ \\
\hline NT1 & $1.08 \pm 0.04$ & $0.53 \pm 0.01$ & $105 \pm 1$ \\
NT2 & $1.10 \pm 0.01$ & $0.54 \pm 0.01$ & $105 \pm 1$ \\
NT3 & $1.14 \pm 0.01$ & $0.56 \pm 0.04$ & $105 \pm 1$ \\
NT4 & $1.14 \pm 0.01$ & $0.62 \pm 0.02$ & $106 \pm 2$ \\
Bio-filter input & $1.12 \pm 0.03$ & $0.56 \pm 0.04$ & $105 \pm 1$ \\
Bio-filter output & $0.98 \pm 0.02$ & $0.53 \pm 0.03$ & $105 \pm 2$ \\
\hline
\end{tabular}

The bacterial communities in RAS play important roles in nutrient removal, but also consume alkalinity. The gradual decline in alkalinity during shrimp cultivation was the major indicator of nitrification (Rurangwa \& Verdegem, 2015). Therefore, the

alkalinity level in the systems requires frequent correction and maintenance within a suitable range for the efficient nutrient removal process.

\subsection{Growth performance of fish}

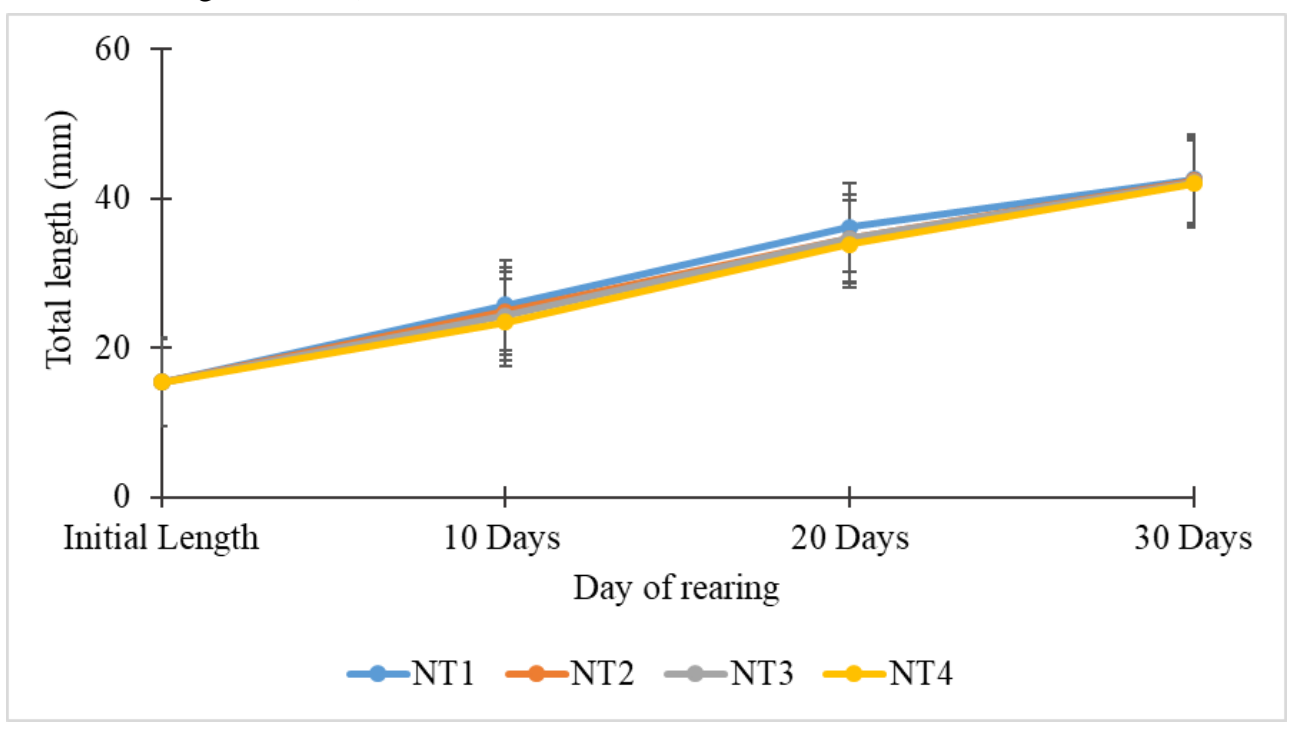

Figure 1. The total length of fish among treatments during the experimental period

Table 4. Growth in length of fish among treatments

\begin{tabular}{lrrrr}
\hline Treatment & $\mathbf{L}_{\mathbf{0}}(\mathbf{m m})$ & $\mathbf{L}_{\mathbf{t}}(\mathbf{m m})$ & DLG $(\mathbf{m m} / \mathbf{d a y})$ & SGR $_{\mathbf{L}}(\boldsymbol{\%} / \mathbf{d a y})$ \\
\hline NT1 & $15.37 \pm 2.40$ & $42.59 \pm 0.13^{\mathrm{c}}$ & $0.907 \pm 0.004^{\mathrm{c}}$ & $3.39 \pm 0.01^{\mathrm{b}}$ \\
NT2 & $15.37 \pm 2.40$ & $42.39 \pm 0.17^{\mathrm{bc}}$ & $0.901 \pm 0.006^{\mathrm{bc}}$ & $3.38 \pm 0.02^{\mathrm{b}}$ \\
NT3 & $15.37 \pm 2.40$ & $42.15 \pm 0.14^{\mathrm{ab}}$ & $0.892 \pm 0.005^{\mathrm{b}}$ & $3.36 \pm 0.01^{\mathrm{a}}$ \\
NT4 & $15.37 \pm 2.40$ & $41.95 \pm 0.13^{\mathrm{a}}$ & $0.886 \pm 0.004^{\mathrm{a}}$ & $3.35 \pm 0.01^{\mathrm{a}}$ \\
\hline$P$ - Value & 0.003 & 0.004 & 0.004 \\
\hline $\begin{array}{l}\text { Alphabetical letters in a column indicate a significant difference among treatments }(\text { ANOVA, Duncan's test, } a<b<c, p \\
<\text { 0.05) }\end{array}$
\end{tabular}

After 30 days of rearing, the fish reached to 41.95 $42.59 \mathrm{~mm}$ with $0.886-0.907 \mathrm{~mm} /$ day of DLG and $3.35-3.39 \%$ /day of $\mathrm{SGR}_{\mathrm{L}}$ (Table 4 and Fig.1). In which, NT1 treatment showed a significantly higher total length, DLG and $\mathrm{SGR}_{\mathrm{L}}$ compared to NT3 and
NT4 $(p<0.05)$, but not NT2 $(p>0.05)$. The length of the fish in NT4 was recorded with the lowest increase in length and was not statistically different compared to NT3. 


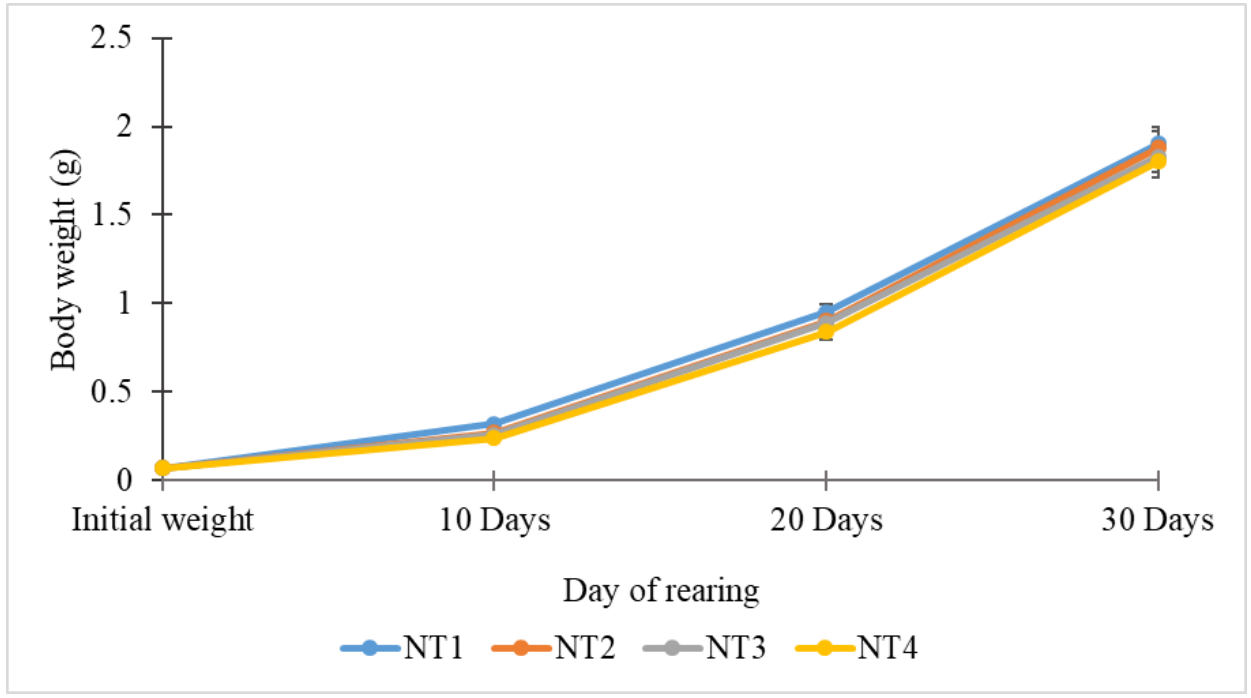

Figure 2. The body weight of fish among treatments during the experimental period

Table 5. Growth in body weight of fish among treatments.

\begin{tabular}{lrrrr}
\hline Treatment & $\mathbf{W}_{\mathbf{0}}(\mathbf{g})$ & $\mathbf{W}_{\mathbf{t}}(\mathbf{g})$ & DWG $(\mathbf{g} / \mathbf{d a y})$ & SGR $_{\mathbf{W}}(\% / \mathbf{d a y})$ \\
\hline NT1 & $0.07 \pm 0.03$ & $1.91 \pm 0.03^{\mathrm{c}}$ & $0.061 \pm 0.001^{\mathrm{b}}$ & $11.01 \pm 0.05^{\mathrm{b}}$ \\
NT2 & $0.07 \pm 0.03$ & $1.88 \pm 0.04^{\mathrm{bc}}$ & $0.060 \pm 0.002^{\mathrm{b}}$ & $10.97 \pm 0.07^{\mathrm{b}}$ \\
NT3 & $0.07 \pm 0.03$ & $1.83 \pm 0.01^{\mathrm{ab}}$ & $0.058 \pm 0.001^{\mathrm{a}}$ & $10.88 \pm 0.02^{\mathrm{a}}$ \\
NT4 & $0.07 \pm 0.03$ & $1.79 \pm 0.02^{\mathrm{a}}$ & $0.057 \pm 0.001^{\mathrm{a}}$ & $10.81 \pm 0.03^{\mathrm{a}}$ \\
$p$ - value & & 0.004 & 0.006 & 0.003 \\
\hline
\end{tabular}

Alphabetical letters in a column indicate a significant difference among treatments (ANOVA, Duncan's test, $a<b<c, p$ $<0.05$ )

On the other hand, the bodyweight of fish ranged from 1.79 to $1.91 \mathrm{~g} /$ fish with $0.057-0.061 \mathrm{~g} /$ day of

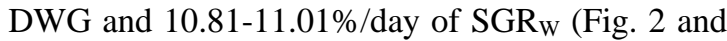
Table 5). The treatment of NT1 and NT2 showed a significantly higher DWG and SGR compared to NT3 and NT4. However, the final body weight of fish in NT2 and NT3 was not statically different ( $p$ $>0.05)$. Remarkably, the NT1 showed the highest body weight $(1.91 \pm 0.03 \mathrm{~g})$, while the lowest body weight was recorded at NT4 $(1.79 \pm 0.02 \mathrm{~g})(p<$ 0.05).

Several studies have been evaluated the effects of stocking density on the performance of marine juvenile fishes such as red porgy (Pagrus pagrus) (Maragoudaki et al., 1999), European sea bass (Dicentrarchus labrax) (Sammouth et al., 2009) and gilthead sea bream (Sparus aurata) (Parma et al., 2020), in which, most of the fish juveniles could adapt well to the high rearing density condition. This study showed the high performance of Pompano $T$. blochi at the stocking density of $500-1000$ juvenile/ $\mathrm{m}^{3}$, it could be explained by the strong schooling behavior of fish (Chavez et al., 2011). However, the pompano is an extremely active fish, so high stocking density in RAS might induce stress and cause growth inhibition (Chavez et al., 2011).

\subsection{Survival rate of fish}

After 30 days of rearing, the survival rate of fish ranged from 96.67 to $98.67 \%$. However, no significant difference was observed among treatments ( $p$ $>0.05$ ). Previous studies also reported high survival of pompano juveniles from 95 to $100 \%$ (Manomaitis et al., 2007; Lan et al., 2007; Chavez et al., 2011). The high survival rate of pompano juveniles in high stocking density conditions could contribute to mass seed production of this species applied RAS technology. 


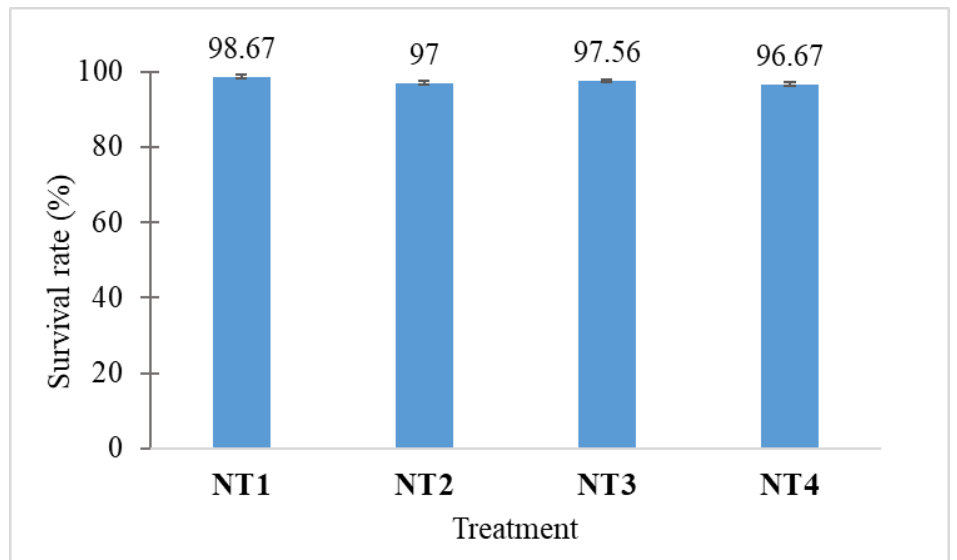

Figure 3. Survival rate of fish among treatments after $\mathbf{3 0}$ days of rearing

\section{CONCLUSION}

Pompano juveniles reared in RAS system proved a hardy and high tolerant fish in the capacity conditions. The RAS system was functionally and stably operated during the experiment lead to the stability of water quality. At $1000 \mathrm{inds} / \mathrm{m}^{3}$ of stocking density in RAS, T. blochii juveniles showed promising results in growth performance and survival rate.

\section{ACKNOWLEDGMENT}

This study is funded by the Can Tho University Improvement Project VN14-P6, supported by a Japanese ODA loan.

\section{REFERENCES}

Badiola, M., Mendiola, D., \& Bostock, J. (2012). Recirculating Aquaculture Systems (RAS) analysis: Main issues on management and future challenges. Aquacultural Engineering, 51, 26-35.

Batty, R. S., Blaxter, J. H. S., \& Richard, J. M. (1990). Light intensity and the feeding behaviour of herring, Clupea harengus. Marine Biology, 107(3), 383-388.

Brest, C. De, Ruyet, J. P.-L., Gaumet, F., Roux, A. L., A.Severe, \& Boeuf, G. (1996). Effects of temperature on growth and metabolism in juvenile turbot. Journal of Fish Biology, 49, 678-692.

Chavez, H. M., Fang, A. L., \& Carandang, A. A. (2011). Effect of stocking density on growth performance, survival and production of silver pompano, Trachinotus blochii, (Lacépède, 1801) in Marine Floating Cages. Asian Fisheries Science, 24(3), 321-330.

Claireaux, G., Couturier, C., \& Groison, A. L. (2006). Effect of temperature on maximum swimming speed and cost of transport in juvenile European sea bass (Dicentrarchus labrax). Journal of Experimental Biology, 209(17), 3420-3428.

Costas, B., Aragão, C., Mancera, J. M., Dinis, M. T., Conceição, L. E. C., \& Refojos, B. C. (2008). High stocking density induces crowding stress and affects amino acid metabolism in Senegalese sole Solea senegalensis (Kaup 1858) juveniles. Aquaculture Research, 39(1), 1-9.

Díaz-Muñoz, D. N., Díaz, N., Torres, O., Leiva, J. C., Palacios, H., Romero, F., \& Benetti, D. (2019). Culture of cobia Rachycentron canadum in a recirculation aquaculture system in Northern Chile. Latin American Journal of Aquatic Research, 47(5), 733-742.

Didrikas, T., \& Hansson, S. (2009). Effects of light intensity on activity and pelagic dispersion of fish: Studies with a seabed-mounted echosounder. ICES Journal of Marine Science, 66(2), 388-395.

Duarte, L. N., Coelho, F. J. R. C., Oliveira, V., Cleary, D. F. R., Martins, P., \& Gomes, N. C. M. (2019). Characterization of bacterioplankton communities from a hatchery recirculating aquaculture system (RAS) for juvenile sole (Solea senegalensis) production. PLOS ONE, 14(1), 1-16.

Dung, L.V., (2015). Effects of stocking density and diets on the survival rate and growth performance of pompano juvenile (Trachinotus blochii Lacepede, 1801). Master thesis in Agriculture. Vinh University

Ellis, T., North, B., Scott, A. P., Bromage, N. R., Porter, M., \& Gadd, D. (2002). The relationships between stocking density and welfare in farmed rainbow trout. Journal of Fish Biology, 61(3), 493-531.

Espinal, C. A., \& Matuli, D. (2019). Recirculating Aquaculture Technologies. In Aquaponics Food Production Systems (pp. 35-74).

Galvan, R., F., Barranco, V., Galvan, J. C., Batlle, Sebastian FeliuFajardo, S., \& García. (2016). Biodegradation of Nitrogen in a Commercial Recirculating Aquaculture Facility. In Biodegradation Engineering and Technology (pp. 341-363).

Hanh, N.V., (2007). Seed production of silver pompano (Trachinotus blochii Lacepede, 1801). Project report, Bac Ninh Fisheries College.

Ha, T.T., (2014). Rearing silver pompano (Trachinotus blochii) in cement tanks. Bachelor thesis in Aquaculture, Nha Trang University 
Irwin, S., O’Halloran, J., \& Fitzgerald, R. D. (1999). Stocking density, growth and growth variation in juvenile turbot, Scophthalmus maximus (Rafinesque). Aquaculture, 178(1-2), 77-88.

Jayakumar. R and Nazar. A. K. A., (2013). Marine fish hatchery concept. design and construction. Mandapam regional center of CMFRI. Mandapam camp - 623520. Tamil Nadu. India. 12p.

Kramer, D. L. (1987). Dissolved oxygen and fish behavior. Environmental Biology of Fishes, 18(2), 81-92.

Kroupova, H., Machova, J., \& Svobodova, Z. (2005). Nitrite influence on fish: A review. Veterinarni Medicina, 50(11), 461-471.

Laiz-Carrión, R., Viana, I. R., Cejas, J. R., Ruiz-Jarabo, I., Jerez, S., Martos, J. A., Eduardo, A. B., \& Mancera, J. M. (2012). Influence of food deprivation and high stocking density on energetic metabolism and stress response in red porgy, Pagrus pagrus L. Aquaculture International, 20(3), 585-599.

Lan, H.P., M.C. Cremer, J. Chappell, J. Hawke and T. O'Keefe., (2007). Growth performance of Pompano (Trachinotus blochii) fed fishmeal and soy based diets in offshore OCAT

Ocean Cages. Results of the 2007 OCAT Cage Feeding Trial in Hainan, China. http://www.soyaqua.org/pdf3/07OCAT

Makori, A. J., Abuom, P. O., Kapiyo, R., Anyona, D. N., \& Dida, G. O. (2017). Effects of water physicochemical parameters on tilapia (Oreochromis niloticus) growth in earthen ponds in Teso North Sub-County, Busia County. Fisheries and Aquatic Sciences, 20(1), 1-10.

Maragoudaki, D., Paspatis, M., \& Kentouri, M. (1999). Influence of stocking density on growth of juvenile red porgy Pagrus pagrus L. under different feeding conditions. Aquaculture Research, 30(7), 501-508.

Manomaitis, L. and C.M. Cremer., (2007). Performance of pompano fed soy-optimized, extruded feed using ASA-IM low volume high density cages in Vung Tau province, Vietnam. Results of ASA-IM/Soy-inAquaculture 2007, Feeding Demonstration Project. American Soybean International Marketing (ASA-IM).

McCarthy, I., Moksness, E., \& Pavlov, D. A. (1998). The effects of temperature on growth rate and growth efficiency of juvenile common wolffish. Aquaculture International, 6(3), 207-218.

Moretti A., Fernandex-Criado M.P., Vetillart R., (2005). Manual on Hatchery Production of Seabass and Gilthead Seabream Volume 2 FAO. Rome. 163pp

Ni, M., Wen, H., Li, J., Chi, M., Bu, Y., Ren, Y., Zhang, M., Song, Z., \& Ding, H. (2014). The physiological performance and immune responses of juvenile Amur sturgeon (Acipenser schrenckii) to stocking density and hypoxia stress. Fish and Shellfish Immunology, 36(2), 325-335.
Pfeiffer, T. J., \& Riche, M. A. (2011). Evaluation of a low-head recirculating aquaculture system used for rearing Florida pompano to market size. Journal of the World Aquaculture Society, 42(2), 198-208.

Pulkkinen, J. T., Kiuru, T., Aalto, S. L., Koskela, J., \& Vielma, J. (2018). Startup and effects of relative water renewal rate on water quality and growth of rainbow trout (Oncorhynchus mykiss) in a unique RAS research platform. Aquacultural Engineering, 82(June), 38-45.

Rurangwa, E., \& Verdegem, M. C. J. (2015). Microorganisms in recirculating aquaculture systems and their management. Reviews in Aquaculture, 7(2), 117-130.

Sammouth, S., d'Orbcastel, E. R., Gasset, E., Lemarié, G., Breuil, G., Marino, G., Coeurdacier, J. L., Fivelstad, S., \& Blancheton, J. P. (2009). The effect of density on sea bass (Dicentrarchus labrax) performance in a tank-based recirculating system. Aquacultural Engineering, 40(2), 72-78.

Sim. S. Y., Rimmer. M. A., Toledo. J. D., Sugama. K., Rumengan. I., Williams. K \& Phillips. M. J., (2005). A guide to small-scale marine finfish hatchery technology. NACA. Bangkok. Thailand. 17pp

Shao, T., Chen, X., Zhai, D., Wang, T., Long, X., \& Liu, Z. (2019). Evaluation of the effects of different stocking densities on growth and stress responses of juvenile hybrid grouper $\circ$ Epinephelus fuscoguttatus $\times$ $\widehat{\delta}$ Epinephelus lanceolatus in recirculating aquaculture systems. Journal of Fish Biology, 95(4), 1022-1029.

Sri-uam, P., Donnuea, S., Powtongsook, S., \& Pavasant, P. (2016). Integrated multi-trophic recirculating aquaculture system for nile tilapia (Oreochlomis niloticus). Sustainability (Switzerland), 8(7), 1-15.

Suantika, G., Situmorang, M. L., Kurniawan, J. B., Pratiwi, S. A., Aditiawati, P., Astuti, D. I., Azizah, F. F. N., Djohan, Y. A., Zuhri, U., \& Simatupang, T. M. (2018). Development of a zero water discharge (ZWD) - Recirculating aquaculture system (RAS) hybrid system for super intensive white shrimp (Litopenaeus vannamei) culture under low salinity conditions and its industrial trial in commercial shrimp urban farming in G. Aquacultural Engineering, 82(December 2017), 12-24.

Timmons, M. B., S. T. Summerfelt, \& B. J. Vinci., (1998). Review of circular tank technology

and management. Aquaculture Engineering 18(1):51-69

Teletchea, F. (2015). Domestication of marine fish species: Update and perspectives. Journal of Marine Science and Engineering, 3(4), 1227-1243.

Zhang, S. Y., Li, G., Wu, H. B., Liu, X. G., Yao, Y. H., Tao, L., \& Liu, H. (2011). An integrated recirculating aquaculture system (RAS) for landbased fish farming: The effects on water quality and fish production. Aquacultural Engineering, 45(3), 93-102. 